\title{
Sistem Informasi Kepegawaian Berbasis Website pada Dinas Pariwisata Dan Kebudayaan
}

\author{
Olha Musa \\ e-mail: 0lh4mu54@gmail.com \\ Manajemen Informatika, STMIK Ichsan Gorontalo \\ Sistem Informasi, STMIK Ichsan Gorontalo
}

\begin{abstract}
Personnel Information System is an information system designed to facilitate the management and storage of employee data. Based on research at the Department of Tourism and Culture of Tojo UnaUna Regency, Central Sulawesi Province, problems found that employee data generated from the existing system did not meet the needs so researchers wanted to design a Staff Information System to solve problems that existed at the research site. This study uses whitebox and blackbox testing. Whitebox testing is testing with trial techniques on program flow, logic structure and program procedures by flowchart mapping, then calculating the number of edges and nodes. The blackbox testing method focuses on the functional interests of the software. Therefore the blackbox trial allows software developers to create a set of input conditions that will train all the functional requirements of a program whether it runs as expected or vice versa.

Based on the results of the whitebox test on one of the processes in this system, namely in the module proposed for promotion with a balanced yield gain, namely Cyclomatic Complexity $(C C)=4$, then this system is declared to work well. While the results of testing the blackbox system can run as expected and efficien.
\end{abstract}

Keywords—Information systems, staffing, Website, php

Intisari- Sistem Informasi Kepegawaian adalah sistem informasi yang dirancang untuk mempermudah dalam pengelolaan dan penyimpanan data pegawai. Berdasarkan penelitian pada Dinas Pariwisata dan Kebudayaan Kabupaten Tojo Una-una Provinsi Sulawesi Tengah ditemukan permasalahan data pegawai yang dihasilkan dari sistem yang sudah ada belum memenuhi kebutuhan sehingga peneliti ingin merancang Sistem Informasi Kepegawaian untuk memecahkan permasalahan yang ada di tempat penelitian tersebut.

Penelitian ini menggunakan pengujian whitebox dan blackbox. Pengujian whitebox adalah pengujian dengan teknik uji coba pada alur program, struktur logika dan prosedur program dengan cara pemetaan flowchart, kemudian menghitung besarnya jumlah edge dan node. Metode pengujian blackbox memfokuskan pada kepentingan fungsional dari software. Oleh karena itu uji coba blackbox memungkinkan pengembang software untuk membuat himpunan kondisi input yang akan melatih seluruh syarat-syarat fungsional suatu program apakah berjalan sesuai yang diharapkan atau sebaliknya. Berdasarkan hasil pengujian whitebox pada salah satu proses dalam sistem ini yaitu pada modul usulan kenaikan pangkat dengan perolehan hasil yang seimbang yaitu Cyclomatic Complexity $(\mathrm{CC})=4$, maka sistem ini dinyatakan dapat berjalan dengan baik. Sedangkan hasil pengujian blackbox sistem dapat berjalan sesuai dengan yang diharapkan dan efisien.

Kata Kunci-Sistem informasi, kepegawaian, Website, php

I. PENDAHULUAN

Menurut Undang-Undang RI No.43 Tahun 1999 tentang Perubahan atas Undang-Undang No. 8 Tahun 1974 tentang PokokPokok Kepegawaian yaitu pegawai negeri adalah setiap warga negara Republik Indonesia yang telah memenuhi syarat yang ditentukan, diangkat oleh pejabat yang berwenang dan diserahi tugas dalam suatu jabatan negeri, atau diserahi tugas negara lainnya, dan digaji berdasarkan peraturan perundang-undangan yang berlaku [1]. 
Undang-Undang Pokok Kepegawaian yaitu Undang-Undang No. 8 Tahun 1974 telah dirubah melalui Undang-Undang Nomor 43 Tahun 1999 tentang Pegawai Negeri Sipil, dan diatur lebih lanjut melalui Peraturan Pemerintah Nomor 53 Tahun 2010 Tentang Disiplin Pegawai Negeri adalah suatu landasan hukum untuk menjamin pegawai negeri dan dapat di jadikan dasar untuk mengatur penyusunan aparatur negara yang baik dan benar. Tujuan dari pemerintah mengeluarkan peraturan ini adalah untuk menjamin tata tertib dan kelancaran tugas Pegawai Negeri Sipil, sehingga dalam bertugas dan menjalankan tugas pokok dan fungsinya sebagai aparatur pemerintahan dapat berjalan semestinya, yang pada akhirnya dapat mendukung pembangunan di Indonesia [2].

Dinas Pariwisata dan Kebudayaan merupakan salah satu instansi pemerintah yang bergerak dalam bidang pelestarian serta pemberdayaan pariwisata dan kebudayaan yang ada di Kabupaten Tojo Una-Una. Saat ini jumlah pegawai yaitu sebanyak 37 orang. Pada saat ini pengolahan data kepegawaian pada Dinas Pariwisata dan Kebudayaan Kabupaten Tojo Una-Una sudah dilakukan dengan terkomputerisasi, artinya data yang mengenai kepegawaian sudah berada di dalam suatu computer dalam desktop Microsoft Office pada bagian kepegawaian. Hal ini masih memiliki kekurangan dan masih belum menyempurnakan kinerja hanya dengan file excel dan word.

Dengan dibuatnya sistem informasi kepegawaian berbasis website ini nantinya dapat merancang suatu sistem untuk menghasilkan sistem yang maksimal dalam pengelolaan data pegawai agar terolah dengan baik, serta ketelitian dan kebenaran informasi yang dihasilkan, sehingga dapat meningkatkan produktivitas kerja pada Dinas Pariwisata dan Kebudayaan Kabupaten Tojo Una-Una Provinsi Sulawesi Tengah. Dari latar belakang diatas maka peneliti mengambil judul "Sistem Informasi Kepegawaian Berbasis Web Pada Dinas Pariwisata dan Kebudayaan Kabupaten Tojo Una-Una Provinsi Sulawesi Tengah”.

\section{TUJUAN PENELITIAN}

Tujuan dalam penelitian ini adalah

Merancang sistem informasi kepegawaian berbasis website untuk menghasilkan sistem yang maksimal dalam pengelolaan data administrasi pegawai secara efektif dan efisien. Studi Kasus Dinas Pariwisata Dan Kebudayaan Kabupaten Tojo Una-Una Provinsi Sulawesi Tengah

\section{METODE PENELITIAN}

\section{A. Metode Penelitian}

Penelitian ini menggunakan metode Research and Development atau yang dikenal dengan metode Penelitian dan Pengembangan. Metode ini didefinisikan sebagai metode penelitian yang digunakan untuk menghasilkan produk tertentu dan menguji keefektifan produk tersebut [19]. Sejalan dengan hal tersebut, Sudaryono mendefinisikan penelitian dan pengembangan sebagai suatu proses pengumpulan dan analisis data dilakukan secara sistematis dan logis untuk mecapai tujuan tertentu [20]. Research and Development membagi metode menjadi 3 bagian dalam penelitian yaitu [19] :

a. Deksriptif. Digunakan dalam studi awal untuk menghimpun data kondisi yang ada yaitu perbandingan kondisi produk

yang sudah ada dan yang akan dikembangkan, kondisi pihak pengguna, kondisi faktor pendukung dan penghambat.

b. Evaluatif. Digunakan untuk mengevaluasi proses uji coba pengembangan suatu produk.

c. Eksperimen. Digunakan untuk menguji keampuhan produk yang dihasilkan.

\section{B. Tahap Desain}

Tahap desain database, dimana semua proses membuat, membaca, memperbaharui, dan menghapus (create, read, update, delete) data. Data disimpan dalam file dan database. Termasuk dalam tahap ini adalah pemodelan field kunci, record table, relasi database, entitas data. kemudian masuk pada tahap desain dan prototyping input dan output serta antar muka sistem, menggambarkan masukan dan keluaran bagi pengguna sistem, baik dalam bentuk formulir masukan, sistem organisasi menu, bentuk cetakan kertas ataupun tampilan ke layar monitor. Implementasi input merupakan masukan input dari keyboard dan mouse, penyesuaian tipe pengguna sistem, penggunaan gambar dan simbol (icon).

\section{Tahap Pengujian}

Melakukan pengetesan terhadap sistem yang telah selesai dibuat sebelum diimplementasikan dengan menggunakan teknik pengujian perangkat lunak yang telah ada yakni menggunakan pengujian White Box dan Black Box Testing.

\section{Tahap Implementasi}

Tahap implementasi sistem yaitu tahap meletakkan sistem agar siap untuk dioperasikan. Penerapan sistem ini yaitu pada Dinas Pariwisata dan Kebudayaan pada bagian kepegawaian dan yang menggunakan aplikasi ini yaitu Pegawai, Admin bagian kepegawaian, Kepala sub.bagian kepegawaian dan Kepala Dinas. 


\section{ANALISIS DAN DESAIN SISTEM}

\section{Sistem yang Sedang Berjalan}

Penyebab Permasalahan, seperti yang telah bahas di atas yaitu Penyimpanan data kepegawaian masih dalam berbentuk arsip yang disimpan dalam sebuah map dan tidak beraturan, sehingga membutuhkan ketelitian tinggi dan memakan waktu yang cukup lama untuk mencari data kepegawaian yang diinginkan serta dapat menyebabkan hilangnya arsip yang telah disimpan. Untuk gambaran lebih jelas tentang sistem yang berjalan dapat dilihat pada diagram use case di bawah ini:

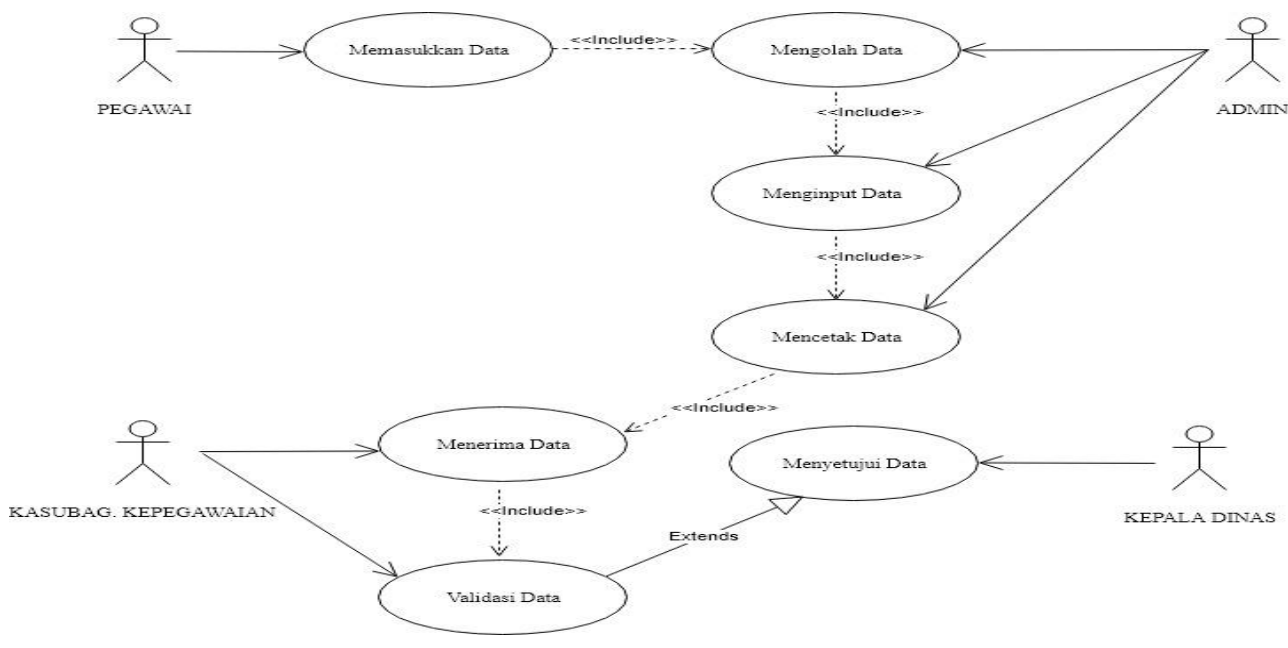

Gambar 4.1. Sistem yang sedang berjalan

Dari use-case sistem yang sedang berjalan di atas, diketahui bahwa user yang terlibat dalam sistem terdiri dari 4 aktor, yaitu: pegawai, admin bagian kepegawaian, kasubag kepegawaian dan kepala dinas. Pada sistem yang berjalan pegawai dapat memasukkan data. Sedangkan pihak admin pada sistem yang sedang berjalan dapat mengolah data, menginput data dan mencetak data, dan bagian kasubag dari sistem yang berjalan dapat menerima data dan validasi data dan kepala dinas dari sistem yang berjalan menyetujui data kepangkatan dari kasubag kepegawaian.

Dari sistem yang sedang berjalan di atas juga diketahui bahwa pelayanan yang diberikan pihak kasubag kepada admin hanya sebatas memverifikasi semua data. Pada sistem yang sedang berjalan juga diketahui bahwa pihak admin tidak dapat memberikan informasi secara akurat kepada pegawai atau masih dilakukan dengan cara manual.

\section{Analisa Sistem yang diusulkan}

Dari hasil analisis sistem yang sedang berjalan di atas menemukan beberapa faktor yang menyebabkan permasalahan tersebut terjadi. Oleh karena itu dengan menggunakan metode yang dipilih mengusulkan rancangan sistem untuk mengatasi permasalahan yang terjadi. Berikut adalah gambaran dari sistem yang direncanakan :

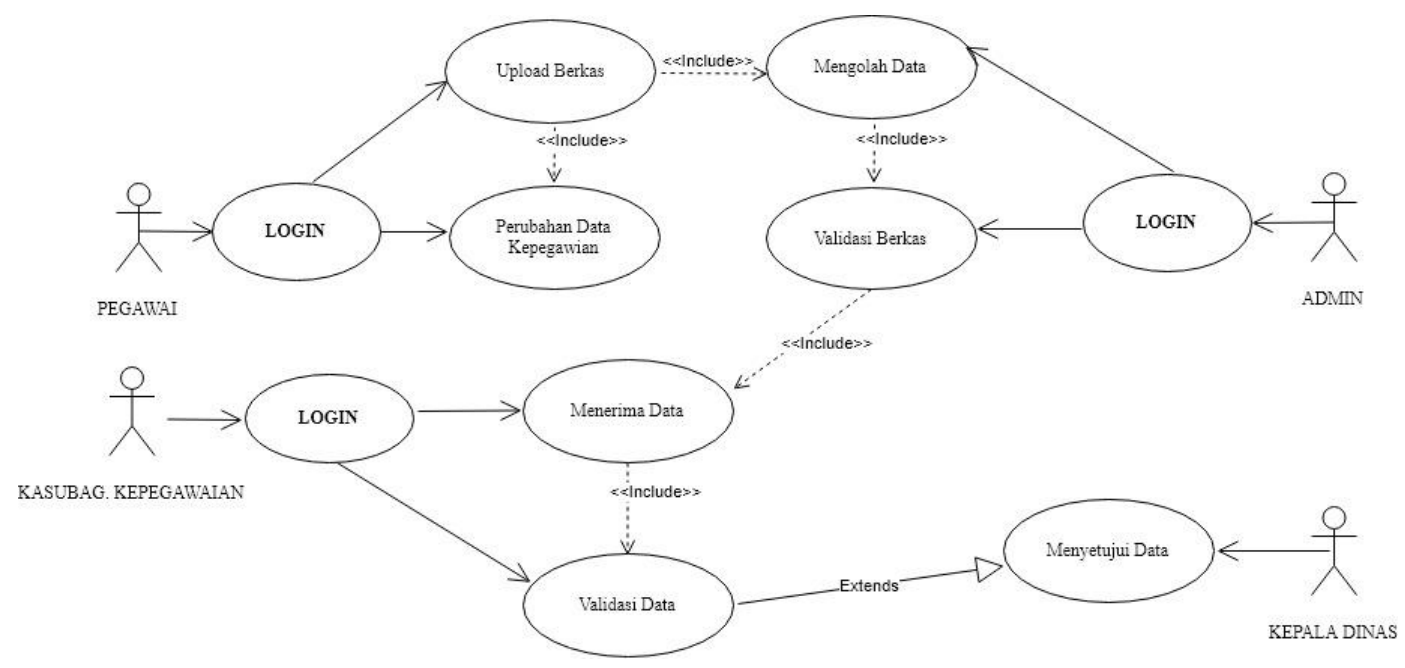




\section{Gambar 4.2 Sistem yang Diusulkan}

Pada sistem yang diusulkan aktor pegawai dapat melakukan login untuk mengakses fitur upload berkas, dan perubahan data kepegawaian oleh sistem.

Pada sistem yang diusulkan pihak admin bagian kepegawaian dapat mengolah data, menginput data pegawai, dan validasi berkas. Pada sistem yang diusulkan pihak kasubag kepegawaian dapat menerima data dan validasi data, dan pada sistem diusulkan pihak Kepala Dinas dapat menyetujui data kepangkatan pegawai. Informasi yang diperbaharui tersebut akan langsung diterima oleh pegawai Desain Sistem Secara Umum

\section{Tampilan Aplikasi}

tampilan Graphic User Interface dari sistem yang diusulkan :

\section{Halaman Login Admin}

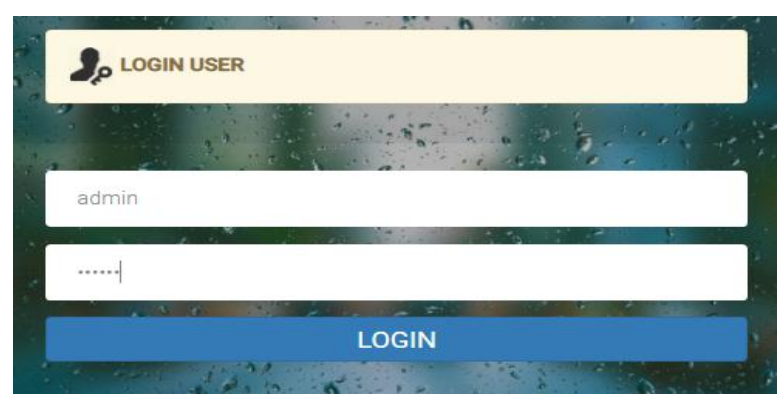

Gambar 4.3 Login

Halaman di atas digunakan untuk login ke halaman Adminsitrator. Administrator disini adalah staff bagian kepegawaian.

\section{Desain Tampilan Utama}

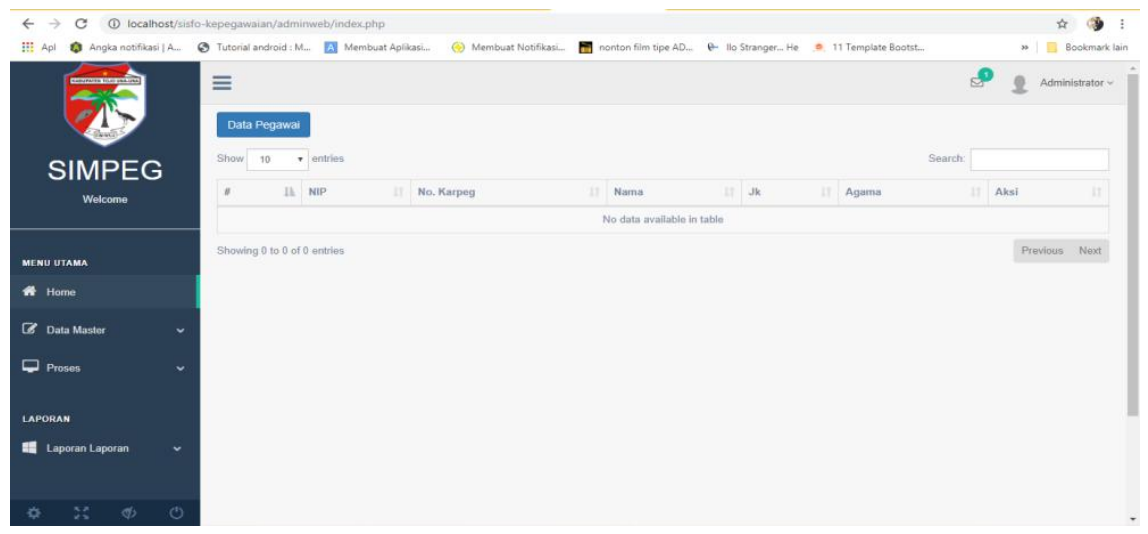

Gambar 4.4 Tampilan Utama

Desain tampilan utama aplikasi sistem informasi kepegawaian akan dirancang seperti tampilan gambar di atas. Halaman ini adalah halaman utama yang akan didapati oleh user pada saat mengakses aplikasi.

\section{Halaman Data Pangkat}




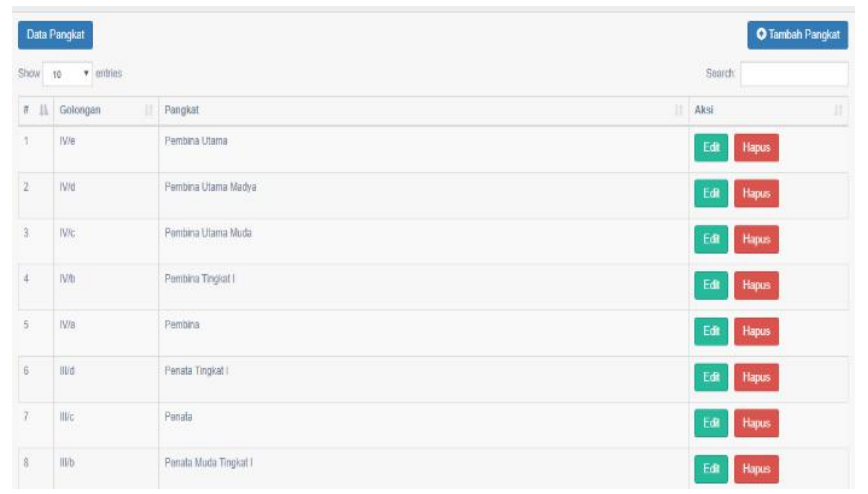

Gambar 4.5 Halaman Data Pangkat

Halaman ini digunakan untuk menampilkan data pangkat. Data pangkat ditambahkan oleh Administrator.

\section{Halaman Data Jabatan}

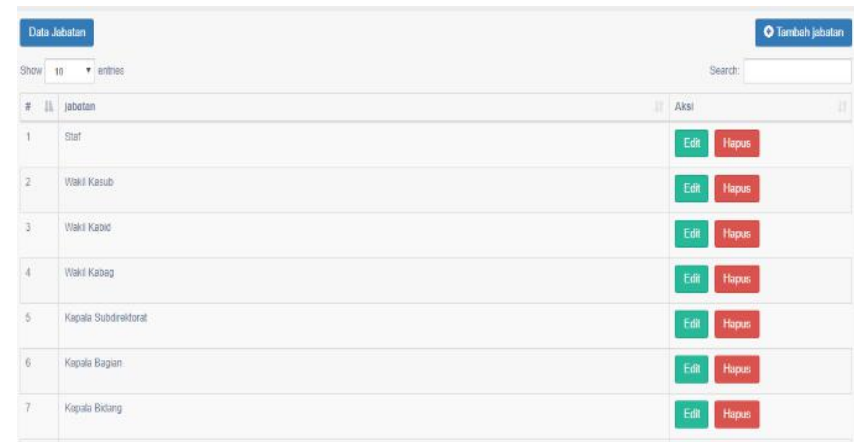

Gambar 4.6 Halaman Data Jabatan

Halaman ini digunakan untuk menampilkan data jabatan. Data jabatan ditambahkan oleh Administrator. Halaman Data Pegawai

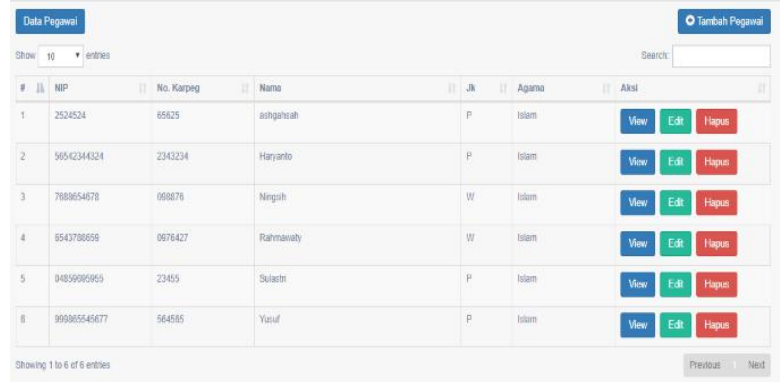

Gambar 4.7 Halaman Data Pegawai

Halaman ini digunakan untuk menampilkan data pegawai. Data pegawai ditambahkan oleh Administrator.

\section{Halaman Data Pangkat Pegawai}

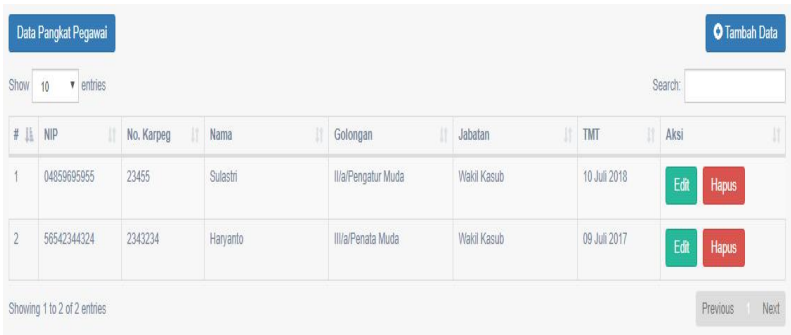

Gambar 4.8 Halaman Data Pangkat Pegawai 
Halaman di atas digunakan untuk menginputkan data pangkat pegawai. Pangkat pegawai diinput oleh administrator.

\section{Halaman Riwayat Diklat}

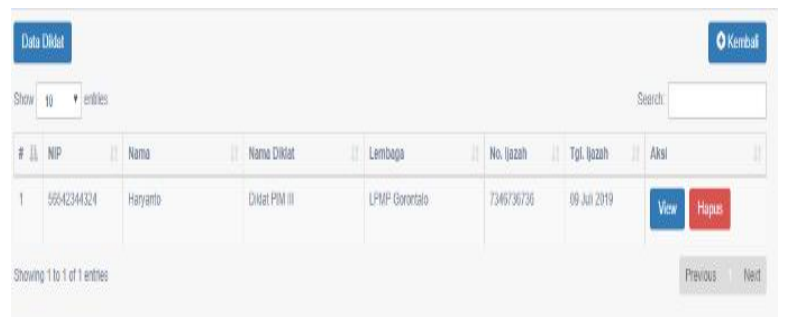

Gambar 4.9 Halaman Riwayat Diklat

Halaman diatas digunakan untuk memantau riwayat diklat yang diikuti pegawai.data riwayat diklat diinput oleh pegawai yang bersangkutan.

\section{Halaman Usulan Kenaikan Pangkat}

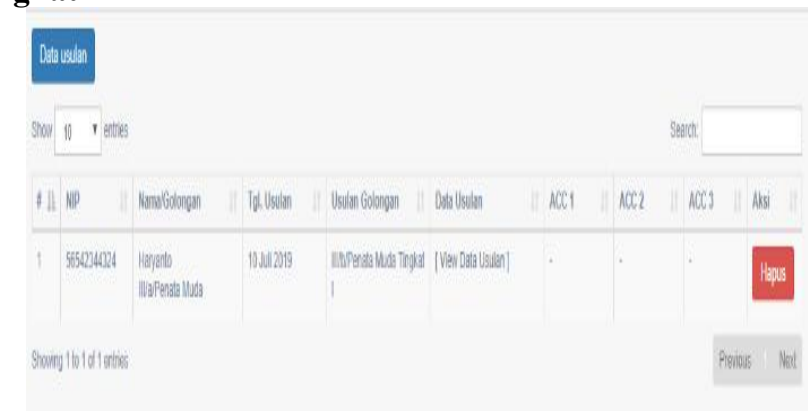

Gambar 4.10 Halaman Usulan Kenaikan Pangkat

Halaman diatas digunakan untuk memantau usulan kenaikan pangkat pegawai. Data usulan kenaikan pangkat diinput oleh pegawai yang bersangkutan, selanjutnya administrator melakukan verifikasi data dengan mengklik view data usulan untuk masing-masing pegawai.

\section{KESIMPULAN}

Dari hasil penelitian di atas maka ditemukan beberapa hal, sebagai kesimpulan, yaitu:

a. Sistem ini dapat memudahkan bagian kepegawaian untuk melakukan pendataan pegawai beserta informasi usulan kenaikan pangkat pegawai.

b. Sistem ini dapat mempermudah pegawai untuk melakukan pengusulan kenaikan pangkat dan mendapatkan informasi tentang usulan kenaikan pangkat.

\section{SARAN}

Saran untuk pengembangan penelitian ini adalah sebagai berikut:

a. Untuk pengembangan aplikasi nanti sebaiknya dikembangkan berbasis android untuk semakin memudahkan pegawai dalam melakukan proses pengusulan kenaikan pangkat.

b. Dinas Pariwisata dan Kebudayaan Kabupaten Tojo Una Una selayaknya memberikan perhatian utama pada pengembangan sistem informasinya terutama aplikasi lewat media komputer dari proses input, pengolahan data, sampai pada proses outputnya.

c. Dinas Pariwisata dan Kebudayaan Kabupaten Tojo Una Una dapat merekrut Pegawai yang profesional dibidang komputer khususnya yang mampu mengelola data melalui komputer 


\section{REFERENSI}

[1] K. K. RI, "Jaringan Dokumentasi dan Informasi Hukum Kementrian Republik Indonesia," 1999. [Online]. Available: https://jdih.kemenkeu.go.id/fullText/1999/43TAHUN 1999UU.htm. [Accessed 1503 2019].

[2] M. Rafik, "PELAKSANAAN DISIPLIN PEGAWAI NEGERI SIPIL (PNS) DI LINGKUNGAN KANTOR KEJAKSAAN NEGERI PALU SULAWESI TENGAH BERDASARKAN PERATURAN PEMERINTAH NOMOR 53 TAHUN 2010," Imu Hukum Legal Opinion, vol. 4, pp. 2-16, 2016.

[3] J. Hutahaen, Konsep Sistem Informasi, Yogyakarta: Deepublish, 2014.

[4] J. Hutahaean, Konsep Sistem Informasi, Yogyakarta: Deepublish, 2014.

[5] J. Hutahean, Konsep Sistem Informasi, Yogyakarta: Deepublish, 2014.

[6] H. Handoko, Manajemen Personalia dan Sumberdaya Manusia, Yogyakarta: BPFE-Yogyakarta, 1989.

[7] D. M. Thoha, Manajemen Kepegawaian Sipil Di Indonesia, Jakarta: Kencana, 2005.

[8] Jasmadi, Membuat Laporan PDF untuk Aplikasi Web Dengan PHP, Jakarta: Elex Media, 2012.

[9] W. and E. , Internet homesite, HTML, dan PHP, Jakarta: Dinastindo, 2012.

[10] Dodit, pintar pemrograman php, Bandung: Bandung oase media, 2008.

[11] e. winardi, "internet homesite HTML dan PHP," Dinastindo, 2012.

[12] S. Dharwiyanti, "Pengantar Unified Modeling Language (UML)," 2003.

[13] Sugiono, Metode Penelitian Kualitatif, Kuantitatif, dan R\&D, Bandung: Alfabeta, 2011.

[14] Sudaryono, S. Guritno and U. Rahardja, Theory and Application of IT Research, Yogyakarta: Andi Offset, 2011.

[15] Y. Pujowati, "Implementasi Kebijakan Peningkatan Pelayanan Kesehatan," Kebijakan dan Manajemen Publik, vol. 3, no. 1, pp. 47-64, April 2012.

[16] K. Febrianto, "Infrastruktur IT Sebagai ‘Key Enabler’ Pendidikan di Indonesia," 10 Maret 2007. [Online]. Available: http://krisnafebrianto.blog.upi.edu/2009/06/17/infrastruktur-it-sebagai-key-enabler-pendidikan-di-indonesia/. [Accessed 10 Januari 2013].

[17] Sugiono, Metode Penelitian Kualitatif, Kuantitatif, dan R\&D, Bandung: Alfabeta, 2011.

[18] I. Y. Arief, "Peran teknologi informasi dan komunikasi di sektor pendidikan indonesia," 22 April 2009. [Online]. Available: http://staff.blog.ui.ac.id/harrybs/2009/04/22/peran-teknologi-informasi-dan-komunikasi-di-sektor-pendidikan-indonesia/. [Accessed 18 January 2013].

[19] L. A. Muharom, "Penerapan Model Presensi Ujian Semester Berbasis Quick Response Code (QR Code) di Universitas Muhammadiyah Jember," JUSTINDO (Jurnal Sistem \& Teknologi Informasi Indonesia), vol. 1, no. 2, pp. 113-122, Agustus 2016

[20] F. F. Rochman, I. K. Raharjana and Taufik, "Implementation of QR Code and Digital Signature to Determine the Validity of KRS and KHS Documents," Scientific Journal of Informatics, vol. 4, no. 1, pp. 8-19, 2017.

[21] Y. T. Widayati, "Aplikasi Teknologi QR ( Quick Response ) Code Implementasi Yang Universal," KOMPUTAKI, vol. 3, no. 1, pp. 66-81, February 2017.

[22] M. P. Nugraha and R. Munir, "Pengembangan Aplikasi QR Code Generator dan QR Code Reader dari Data Berbentuk Image," in Konferensi Nasional Informatika, Bandung, 2011.

[23] E. Ardhianto, W. Handoko and E. N. Wahyudi, "Pengembangan Metode Otentikasi Keaslian Ijasah dengan Memanfaatkan Gambar QR Code," Jurnal Teknologi Informasi DINAMIK, vol. 20, no. 2, pp. 106-114, Juli 2015.

[24] I. G. B. Jawi and H. Supriyono, "Pemindaian QR Code Untuk Aplikasi Penampil Informasi Data Koleksi Di Museum Sangiran Sragen Berbasis Android," Jurnal Emitor, vol. 17, no. 1, pp. 6-8, 2018.

[25] T. Cata, P. S. Patel and T. Sakaguchi, "QR Code: A New Opportunity for Effective Mobile Marketing," Journal of Mobile Technologies, Knowledge and Society, vol. 2013, no. 1, p. 7, 2013.

[26] B. Sugiantoro and F. Hasan, "Pengembangan QR Code Scanner Berbasis Android Untuk Sistem Informasi Museum Sonobudoyo Yogyakarta," TELEMATIKA, vol. 12, no. 2, p. 134 - 145, Juli 2015. 